\title{
Citizens' attitudes towards the public sector, public servants, and politicians - Development and validation of practical survey scales
}

\author{
Jurgen Willems
}

Institute for Public Management \& Governance

Vienna University of Economics and Business

Website | Twitter | ResearchGate | ORCID | OSF

\begin{abstract}
Willems, Jurgen. 2020. "Citizens' Attitudes Towards the Public Sector, Public Servants, and Politicians - Development and Validation of Practical Survey Scales.” OSF Preprints. June 26. https://osf.io/rnjua/
\end{abstract}

\begin{abstract}
This study reports the development and the validation of three related attitude scales that measure the attitudes of citizens towards the public sector, the public servants, and the politicians respectively. With three samples $(\mathrm{n} 1=325, \mathrm{n} 2=320, \mathrm{n} 3=337)$, scale items were assessed based on item-scale correlations, internal consistency, and social desirability. Moreover, convergent and discriminant validity were verified, based on the relatedness of the three attitude scales with several focal constructs from the public management literature, including public service motivation and citizens' trust in government. In addition, this study outlines the avenues for further research on how the use of these scales can advance the field of public management, and particularly behavioral public administration.
\end{abstract}

Key words: Attitudes, public sector, public servants, politicians, scale development, public service motivation, trust in government.

Data: The data and the full analysis protocol (in R) are available for other researchers to retest, elaborate, and compare these scales and data sets with new data collections: Willems, J. (2020, June 18). Public Servants: Stereotypes, attitudes, reputation, and stigmata. Retrieved from https://osf.io/xky93/

The full research protocol (with R code) is on GitHub: https://github.com/MrJurgenWillems/Research/tree/master/Attitudes

Acknowledgements: I thank Steven Van de Walle, Sebastian Jilke, Kristina Weißmüller, Matthias Döring, and Dominik Vogel for suggesting the related scales, which were highly relevant for testing convergent and discriminant validity of the attitude scales. I would also like to express my gratitude to Lewis Faulk, Sebastian Jilke, Steven Van de Walle, Dominik Vogel, and Kristina Weißmüller for their feedback on the earlier versions of this article. 


\section{Introduction}

In recent years, the topic of citizen attitudes towards the public sector and public servants have gained importance in academic literature (James, Jilke, and Van Ryzin 2017; Grimmelikhuijsen et al. 2017). For example, Marvel (2016) finds a consistent negative perception among citizens about public service performance as compared to business performance. In parallel, negative widespread stereotypes about public servants have also been identified as an area that needs further attention (Van de Walle 2004). Similarly, citizen attitudes towards politics and politicians have been identified as a crucial factor in the behaviors of citizens to participate in public processes (Nielsen 1981; Inthorn and Street 2011; Henn, Weinstein, and Forrest 2005). With an increased research focus on citizens' attitudes towards the public sector, public servants, and politicians, we can better understand the individual behaviors of citizens in their interaction with public institutions and their interactions with public officials within those institutions (Grimmelikhuijsen et al. 2017). As a consequence, the public management field can substantially benefit from tools that enable us to further explore the differences in the engagement of citizens with public institutions.

However, the present public administration field misses some broadly-applicable attitude measures that can be used for a wide variety of research questions and contexts. It is due to this deficiency that the current approach to quantify the attitudes of citizens often consists of context-specific measures which have been developed for a specific analysis (for example, in specific experiment designs), or for the use of proxy-measures which only partially relate to the actual attitudes of the citizens (e.g. when secondary data is used from public service evaluation surveys). Despite the fact that such earlier studies have great value for theorizing on the attitudes of citizens, the lack of uniform measures hampers the generalization of findings and the replication in other settings.

Moreover, the attitudes of citizens can focus on very distinct entities. Research on attitudes has its origin in social psychology (Thurstone 1928), and it focuses on explaining the individual differences in human behaviors in relation to a variety of entities (Eagly and Chaiken 2007). Such entities can be very concrete, such as pertaining to a particular person (e.g. a politician), or very abstract (e.g. an ideology). The field of public administration has dealt with the behavior of citizens in the context of a broad range of relevant entities. However, few studies have focused on how behavior of citizens is different based on their attitudes towards distinct public entities. For instance, the overall and abstract government entity contains more specific entities, such as politicians, on the one hand, who make policies on how public institutions should function, and public institutions, on the other hand. Within these institutions, public servants are an even more specific entity that has been widely studied in the field of public administration. As attitudes can be very different for each of these entities, human behavior is potentially also driven differently by them. Hence, the research field could thereby additionally benefit from measurements, each of which focus on specific entities within the broad area of government services.

This study reports on the development and the validation of three distinct, yet related, attitude scales. Such survey scales can help verify theoretical claims and identify avenues for further research. Hence, attitude scales in the field of public services can especially advance research that focuses on explaining the differences within heterogeneous populations. For example, in the research area related to public service biases, attitude studies can add a substantial nuance by 
clarifying the extent to which certain individuals are more susceptible to such biases as compared to others. In addition, other streams in the field of public management can benefit from such tools, as attitudes potentially relate to the expectations and the cognitive processes in public performance evaluations (Ryzin 2004; Jilke 2017), the choice of being involved in citizen participation initiatives and co-production (Whitaker 1980; Irvin and Stansbury 2004 ; Clark and Jang 2013; Roberts 2004; Willems, 2017), as well as the decision to enter into public service careers (De Cooman et al. 2011; Becker and Connor 2005; Goulet and Frank 2002; Willems 2014).

Given the aim of developing and validating measurement scales that are helpful for other studies, a set of methodological choices has been made based on four specific goals. First, the study focuses on developing scales that are sufficiently concise (one-dimensional constructs), so that they can easily be integrated in surveys and/or experiment questionnaires, which also contain other constructs. Second, three uni-dimensional scales have been developed in combination and in relation to each other. In doing so, this study provides an insight into the extent to which attitudes towards different entities are similar or distinct. This enables scholars to choose the right entity focus while performing further studies and the appropriate scale to measure it. Third, in order to make the verification quantitative, scales were measured in two different ways (once with all items randomized, and once with the items presented as per entity). This provides an insight as to how the questionnaire format affects the reliability of a scale. This knowledge can additionally be used by scholars to conduct further attitude studies. Finally, the scale content was developed to be relevant across many contexts, and, as a consequence, the focus was not made on specific public services or government responsibilities, nor on a specific national or regional context.

Attitudes can be measured towards a broad range of entities, such as an organization, a product, an ideology, an individual, or a group of people (Gawronski 2007). Three focal entities were chosen from a broad range of potentially relevant government-related entities: the public sector, public servants, and politicians. A separate attitude scale was developed and validated for each of these foci. Simultaneously validating these three scales enabled clarifying both the relatedness and the distinctness of citizen attitudes towards these three entities. Hence, the choice was made not to develop a scale that focused only on one entity or a concept with several sub-dimensions (e.g. four sub-dimensions in the overall construct of public service motivation (Kim et al. 2013; Perry and Wise 1990) or three dimensions in citizens' trust in governmental organizations (Grimmelikhuijsen and Knies 2017)), but on the simultaneous validation of three related, but distinct, scales. Therefore, the next section provides an insight into the theoretical background, which is at the basis for simultaneously deriving scale items for these three entities. The methodology section reports on the various tests that have been done to assess scale validity, based on three data samples. In the discussion section, attention has been paid to how a stronger focus on individual attitudes in public management can advance various research streams.

\section{Citizen attitudes in the public sector and political context}

Attitudes can be defined as "a psychological tendency that is expressed by evaluating a particular entity with some degree of favor or disfavor" (Eagly and Chaiken 1993, 1; cited in Gawronski 2007, p575). As a result, attitudes can be measured towards a broad set of entities, including people, organizations, 
products, ideas, ideologies, groups in society, sectors, nationalities, etc. (Eagly and Chaiken 2007) Moreover, attitudes can be measured among the general population, or among certain groups, such as youth, the workforce, managers, or customers.

Since Thurstone (1928) introduced attitudes as a measurable construct, attitudes have "become one of the most important constructs in social psychology. In fact, it is difficult to imagine what contemporary social psychology would be like without the concept of attitude" (Gawronski 2007, p573). The concept of attitudes has established itself as a crucial factor to explain individual behavior not only within social psychology, but within a wide range of social sciences and disciplines.

With respect to various entities in the field of government research, attitudes have been measured and analyzed within a broad range of research fields and sub-domains. One such domain focuses on job attitudes of the public servants themselves, in which job attitudes are analyzed as a function of organizational context and management practices (GouldWilliams 2004; Albrecht and Travaglione 2003). For example, Vigoda (2000) investigated the effect of organizational politics in public institutes regarding the attitudes of public servants towards their own jobs and have found a negative effect on the organizational politics.

From the perspective of a citizen, the focus of the research has been made on attitudes towards particular services and their public nature, such as public versus private transport (Beirão and Cabral 2007), e-governance and e-government (Kolsaker and Lee-Kelley 2008), and wind-power policies (Ek 2005). On a more abstract level, attitudes towards democracy explain people's trust in government and in public sector reforms (Christensen and Lægreid 2003). Moreover, attitudes towards politics in general can further be subdivided, as they can vary differently for distinct government levels (Nielsen 1981). This shows that it is appropriate to make a distinction between the operational public services aspect of government and the strategic, political component of it.

In contrast to the more abstract level of attitudes towards government-related entities, very specific individuals can also be the focal entities of research. For example, Inthorn and Street (2011) investigate how celebrity politics, which is the process by which popular celebrities openly endorse politicians and their political programs, can influence the attitudes of youth towards politics. Their research suggests that strongly communicated authenticity about politicians can improve the attitudes of youths towards politics, which, in turn, can influence the choice of young citizens to vote (Henn, Weinstein, and Forrest 2005).

A specific stream of literature has focused on whether the overall attitudes towards government-related entities are either positive or negative. As compared to the private for-profit sector, studies have found that people have a negative attitude towards public service entities (e.g. Marvel 2016). For example, the public sector is often typified as being bureaucratic, slow, and inefficient (Pandey, Coursey, and Moynihan 2007; Marvel 2016; Olsen 2015), which might, in turn, influence the overall attitudes of citizens about public servants and about the political systems in which they operate (Bean and Papadakis 1998). For example, public employees are often portrayed as being lazy, risk-averse, or corrupt in popular media and movies, which strengthen the wide-spread stereotypical thinking about them (Van de Walle 2004). 


\section{Methodology}

Developing and validating the related scales happened in five steps, following general recommendations on scale development and validation (Bollen and Richard 1991; Foddy 1993; Scherpenzeel and Saris 1997; Borsboom, Mellenbergh, and Heerden 2003; DeVellis 2003). Items and scale validations were based on three distinct samples obtained from two large data collections. Respondents were addressed through Amazon Mechanical Turk (MTurk) for all data collections.

All analyses were conducted in R ( $\mathrm{R}$ Core Team 2017), with special use being made of the packages lavaan (Rosseel 2012), psych (Revelle 2017), Scale (Giallousis 2015), and corrplot (Wei and Simko 2017). The original data, along with the complete analysis protocol, can be found in the online appendix. This should encourage other researchers to build on this study to further evaluate the scales (e.g. with alternative methods), compare new data collections with the data samples of this study (e.g. in other languages), and/or perform more advanced and additional analyses (e.g. group comparisons based on demographic background variables).

\section{Step 1: Item generation for three related constructs}

Adding to the literature that has been postulated above, a list of characteristics about the public sector, public servants, and politicians was derived first. Characteristics were further explored based on the publicly available data on 7,470 word associations by 415 U.S. respondents for 12 professions, including public servants and politicians (Willems 2018; Willems 2020). Figures 1 and 2 give the word clouds of most associated words for the categories public servant and politician. These characteristics were then used to develop a series of short survey items. In order to increase content validity, the initial list of items was complemented with lists from individuals who were not associated with the study. Moreover, I started interviewing additional individuals until the lists became redundant and no new items were added. The lists from these interviews included typical associations that are made about the public sector, the public servants, and the politicians by individuals who are not familiar with the academic literature on the subject. This helped verify and extend my initial ideas which were mainly based on the available literature that was reviewed for this study, and it also worked in limiting my own potential personal bias. In all, there were high levels of redundancy across the interviews. This indicated the high degrees of overlapping between academic studies on the subject and lay impressions, and gave confidence that there was a sufficient level of saturation among the items in the study relative to the potential constructs of interest. To avoid acquiescence biases in scale responses (Billiet and Davidov 2008), several items were formulated in the reverse order. In total, 15 items were derived for each focus category (public sector, public servants, and politicians). Subsequently, a final list of 45 items was proofread and evaluated for clarity and exhaustiveness by two native Englishspeaking scholars in the field of public and non-profit management. The full list of items is given in Table 1.

The items were formulated in such a manner that they could be answered with a 7-point Likert scale, whose elements are as follows: 'Strongly disagree' (-3), 'Disagree' (-2), 'Somewhat disagree' (-1), 'Neither agree nor disagree' (0), 'Somewhat agree' (1), 'Agree' (2), 'Strongly agree' (3). The 7-point scale was chosen as it gives the respondents the opportunity to add more nuance to their answers (as compared to a 5-point scale) (Norman 2010; Alwin 1997). 
Figure 1: Cognitive word associations for "public servant" in US (Willems, 2020a; Willems 2020b:

https://doi.org/10.6084/m9.figshare.1250541 5)

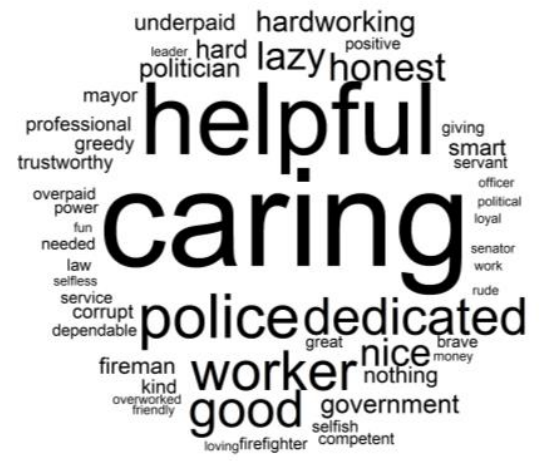

Figure 2: Cognitive word associations for "politician" in US (Willems 2020a; Willems 2020c: https://doi.org/10.6084/m9.figshare.1250543 0)

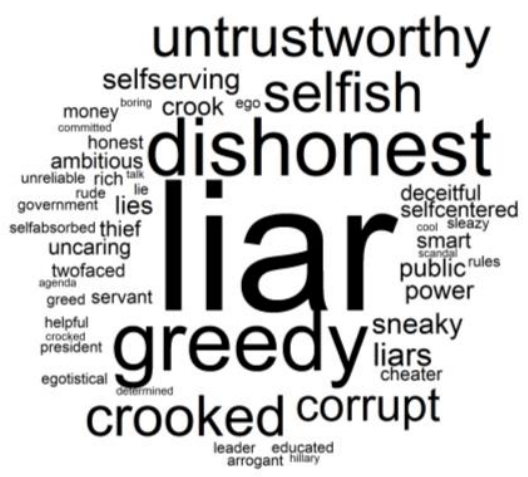

Moreover, the numeric labels from -3 to +3 has the additional advantage that the sign of a scale value informs us about the absolute negativeness or positiveness in terms of attitudes. For example, in a regression in which an (aggregate) attitude score is explained as a dependent variable, a nonsignificant constant means that on an average and with all independent variables being zero, a neutral answer was recorded on the scale. In contrast, a significant positive or negative constant provides an indication whether scales were answered in a particular direction.

\section{Step 2: Analysis of two samples to evaluate item quality and construct reliability}

In this step, two samples were analyzed to evaluate item quality based on the following three criteria: (1) item-scale correlation, (2) item consistency with other items, and (3) social desirability of items.

\section{Design and data collection.}

In the first wave of data collection, 700 MTurk workers in the U.S. completed a questionnaire that would take 10 minutes to complete. Respondents were rewarded with 1.75 U.S. dollars. This is about 10.50 U.S. dollars per hour, which is in line with the call for stronger ethical standards on crowd sourcing workforces (Guidelines for Academic Requesters). However, the compensation was dependent on the fact whether respondents answered basic attention questions correctly throughout the survey. It had been clarified in the assignment to the MTurk workers that payments would be dependent on correctly answering those attention questions.

Data was collected through the means of a Qualtrics survey. Respondents were randomly assigned to one of the two survey streams, which were both analyzed in this study as distinct samples. In one stream, all the 45 items were randomly shuffled and presented in three randomly ordered batches. Hence, in this stream, all the items for all the three scales were asked in a combined manner, and each respondent answered them in different orders. In the second stream, items were grouped as per entity, and thereby, each batch of 15 items focused respectively on the attitudes towards the public sector, the public servants, and the politicians. However, the items within these entity-focused batches where randomized, and the batch order was also randomized (all with the Qualtrics randomization functionality). 


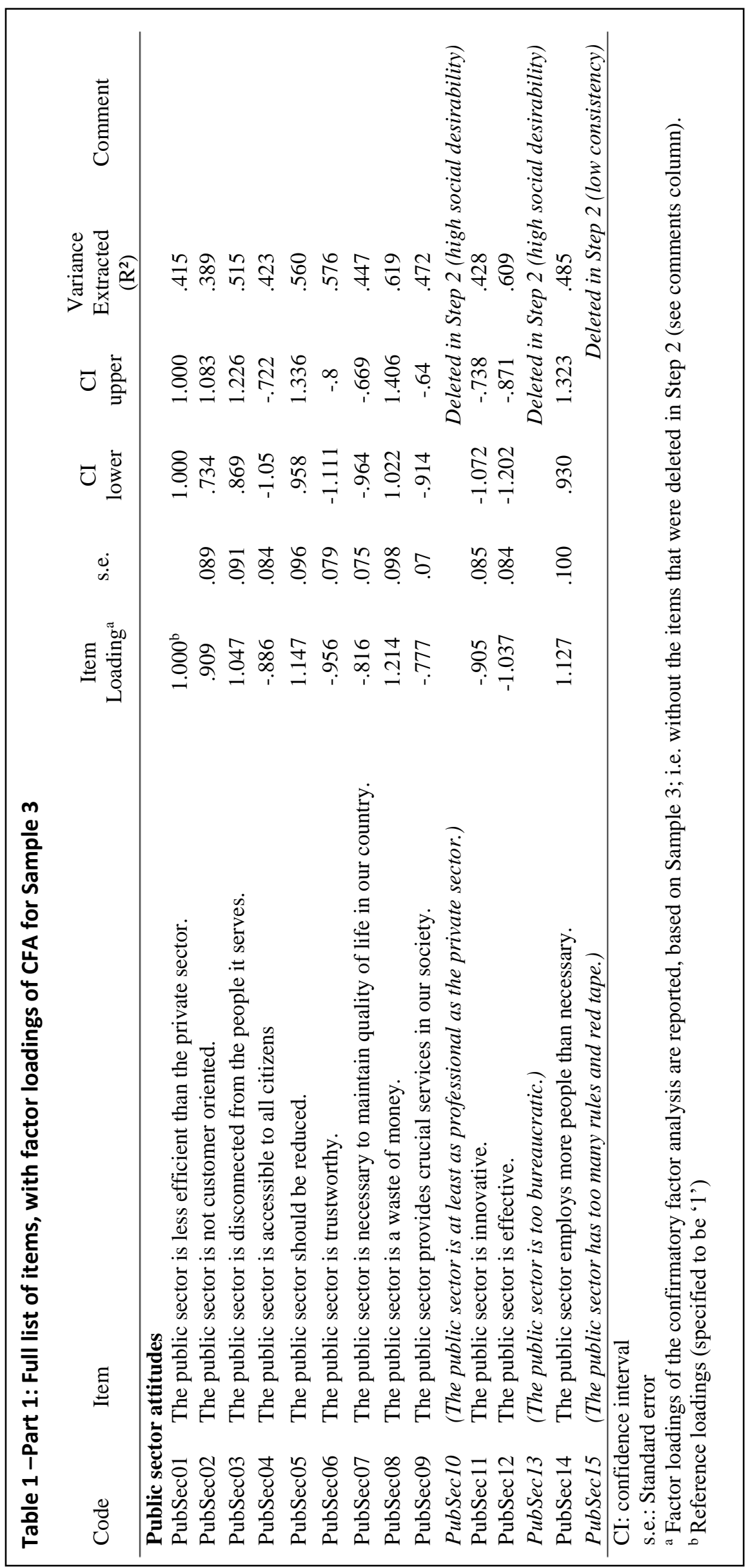




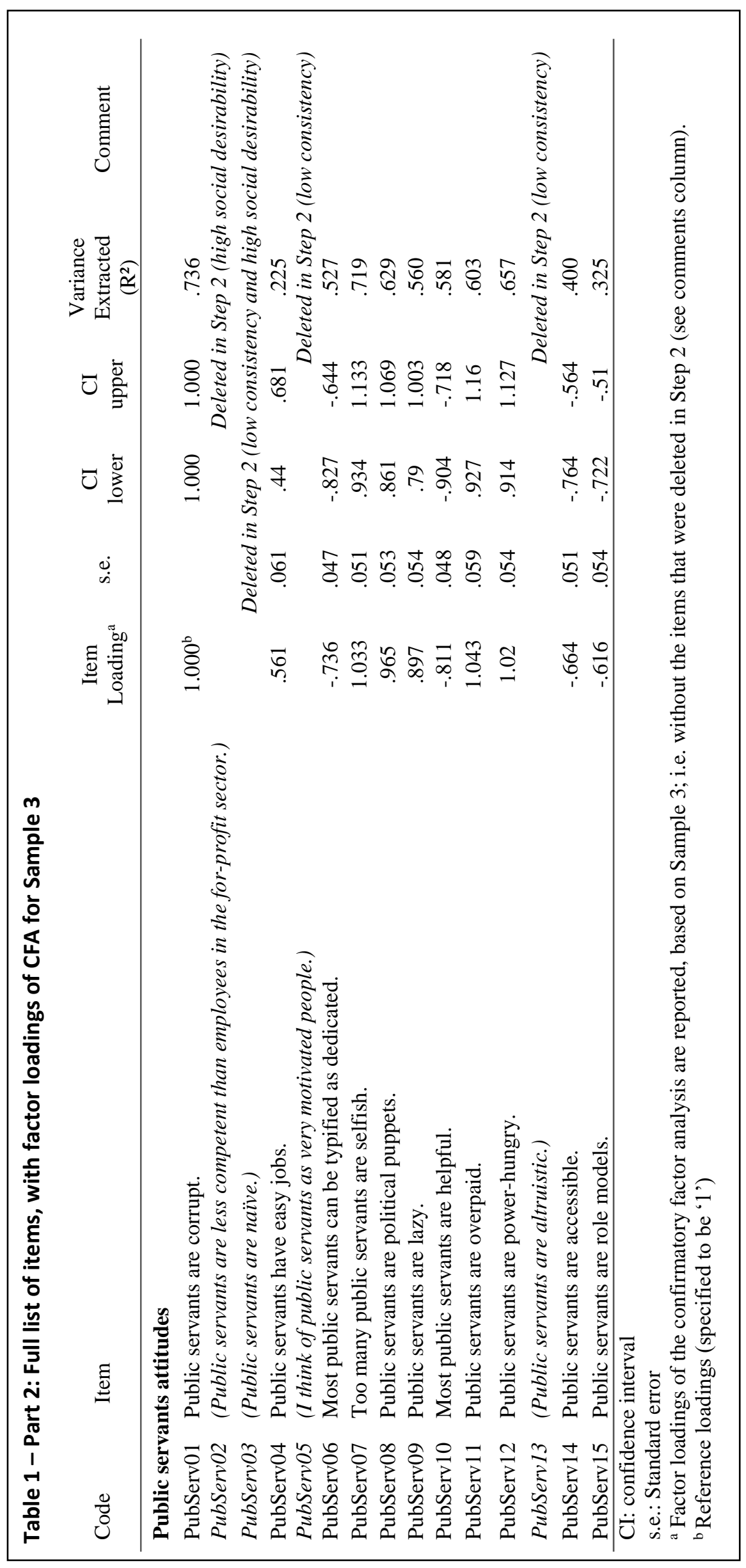




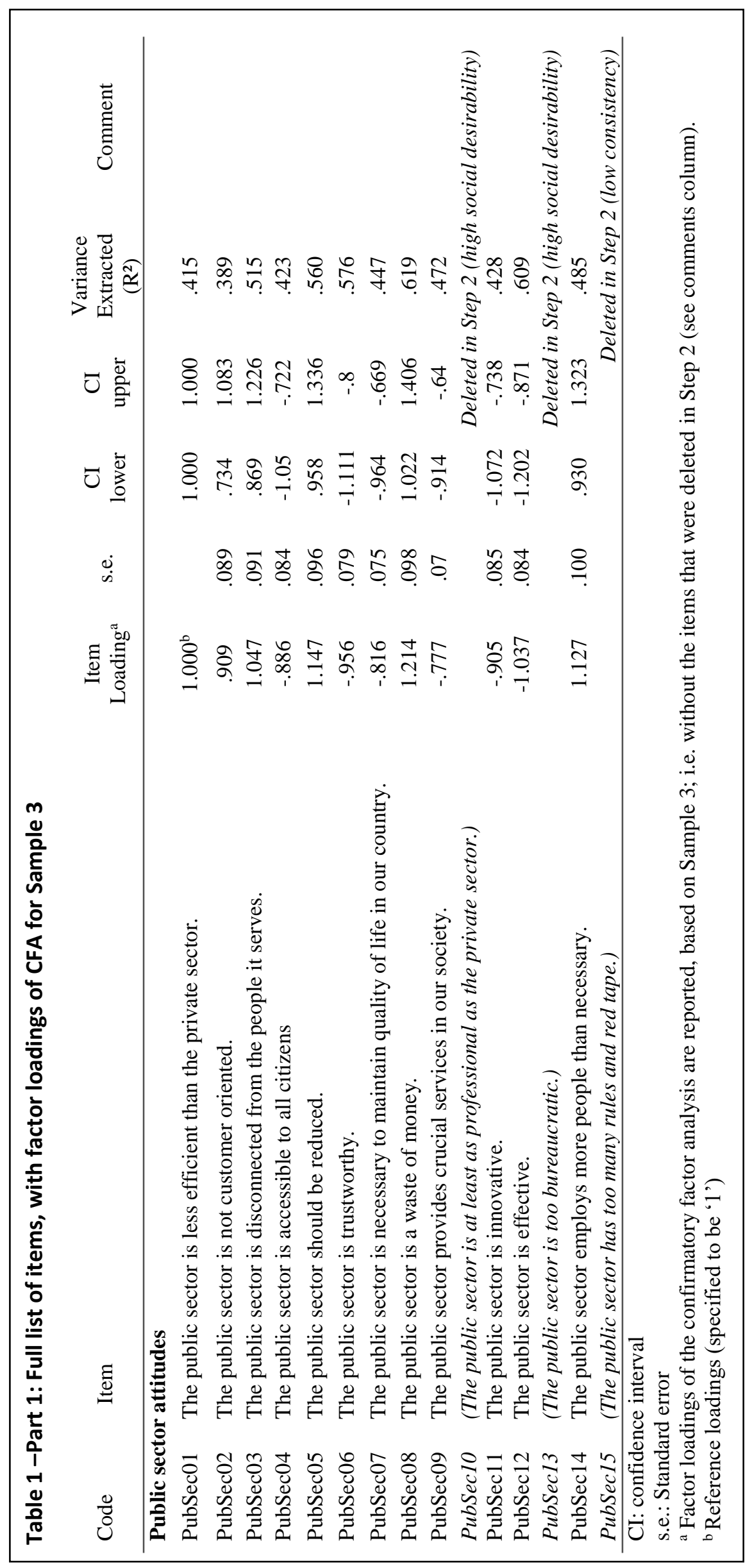


As has been shown by a substantial body of literature, question order can influence the response behavior (Van de Walle and Van Ryzin 2011), the randomization of items and batches attempts to reduce consistent biases in answering in the data. This structure also allows analysis of the extent to which item and scale relatedness are influenced by item order. This is further explored in Step 4 of this analysis. In each batch of 15 items, a sixteenth item was added that contained an attention question, such as 'Answer Strongly Disagree here' or 'Answer the middle option here'.

For both the survey streams, the questionnaire was finished with a 10-item construct to measure social desirability (Strahan and Gerbasi 1972) and a set of demographic questions on gender, age, employment status, and education. The construct of social desirability contains items that invoke answering in a socially desirable manner, which means that these items were answered by most people to conform to the social norms rather than represent real behavior and opinions. Including such a scale enabled testing the extent to which new scale items were potentially influenced by a social desirability bias (Fischer and Fick 1993). It is, therefore, a common step in the process of scale validation to delete items that have a strong correlation with a measure of social desirability. By omitting these items, the overall scale is less susceptible to social desirability biases in the responses. Strahan and Gerbasi (1972) developed two interchangeable scales, each containing ten items. For the first wave of data collection, the first set of 10 items is used, while the second data collection of this study contained the second set of 10 items. Cronbach's alpha values for Samples 1 and 2 are 0.81 and 0.83 respectively.

\section{Results.}

In total, 709 respondents started, out of which 702 finished the questionnaire. For 351 respondents, all items of the three constructs were shuffled (325 answered all attention questions correctly), and the remaining 351 were presented with categorized blocks of items (320 answered all attention questions correctly). Thus, a relatively low number of respondents were determined to not be paying sufficient attention while they completed the questionnaire.

Several items were deleted since they either had low correlation with the overall set of items for their respective category (cut-off of 0.4 ) and/or because their deletion would increase the reliability of the set of remaining items. The deleted items were: PubSec15, PubServ03, PubServ05, PubServ13, Pol04, Pol05, Pol12, and Pol14. The following items had significant correlations with the social desirability construct and were, therefore, also deleted: PubSec10, PubSec13, PubServ02, PubServ03, Pol02, Pol05, Pol07, Pol08, Pol09, Pol15. However, it must be said that these items did not all correlate consistently with the social desirability for both samples. So, it is hard to conclude that some items were consistently biased by social desirability. The final reliability measures for the reduced scales all met the traditional criterion of 0.7 .

\section{Step 3: Analysis of a third sample to assess relatedness with other public management constructs (convergent and discriminant validity)}

\section{Design and data collection.}

Statistical relatedness with other public management constructs was evaluated based on a third sample, which was also obtained through MTurk. In total, 350 respondents were sought from the U.S., leading to a total of 353 respondents, who started the questionnaire. All 353 respondents finished the questionnaire, among whom 337 answered all the attention questions correctly. These respondents received a reward of 2 
U.S. dollar reward for completing the questionnaire.

The Qualtrics questionnaire contained the three focal constructs having the remaining items. Cronbach's alpha values are listed as follows: public sector: 0.90; public servants: 0.89 ; politicians: 0.87 . The order of the three attitude pages was randomized for each respondent, and the item order per scale were randomized as well. Similar to the first wave of data collection, each scale was accompanied with an attention question, and respondents who failed to answer all attention questions correctly were removed from further analysis.
Subsequently, all respondents went through eight additional survey pages with the following constructs, for which the order was also randomized for every respondent:

(1) A short version of public service motivation (PSM) (Vandenabeele and Vries 2013). Public service motivation is the motivation for people to engage in the provision of public goods, and it has been studied mainly among public servants (Perry and Wise 1990). Despite the fact that PSM research mainly focuses on motivations of this particular sub-population, it is relevant amongst a broader population too, as it, for example, is used to explain the

Table 2: Descriptive statistics for measured constructs.

Mean s.e. Min. Max.

\begin{tabular}{lcccc}
\hline Attitude scales & & & & \\
Public sector & .20 & .06 & -2.83 & 3.00 \\
Public servants & .00 & .07 & -3.00 & 2.82 \\
Politicians & -1.18 & .06 & -3.00 & 2.00 \\
PSM & & & & \\
PSM (Short) & 1.00 & .07 & -3.00 & 3.00 \\
PSM (APS) & .92 & .04 & -2.00 & 2.00 \\
PSM (CPV) & 1.19 & .04 & -2.00 & 2.00 \\
PSM(COM) & 1.14 & .04 & -2.00 & 2.00 \\
PSM (SS) & .48 & .05 & -2.00 & 2.00 \\
Trust in Government & & & & \\
Competence & -.09 & .05 & -2.00 & 2.00 \\
Benevolence & -.29 & .06 & -2.00 & 2.00 \\
Integrity & -.59 & .05 & -2.00 & 2.00 \\
Government Trust Index (ANES) & 2.77 & .07 & 1.00 & 7.00 \\
Sector employee trust & & & & \\
Trust in government employees & -.53 & .06 & -2.00 & 2.00 \\
Trust in nonprofit employees & .48 & .06 & -2.00 & 2.00 \\
Trust in business employees & -.35 & .06 & -2.00 & 2.00 \\
Public sector feeling & 1.15 & .08 & -3.00 & 3.00 \\
Conservative & -.54 & .08 & -2.00 & 2.00 \\
Social desirability & .18 & .06 & -2.80 & 3.00 \\
\hline n = 327 & & & & \\
\hline
\end{tabular}


willingness to choose a job in the public sector among non-public servants (Y. Choi 2017; Lee and Choi 2016; Wright, Hassan, and Christensen 2017). Hence, it is expected to have a certain degree of convergence with the attitude scales, especially towards the public sector and the public servants. The 4-item shortened version of the scale of Vandenabeele and Vries (2013) has been included in this study as an overall, summarizing measure of the multidimensional construct of PSM. Answers could be given on a 7-point Likert scale, ranging from strongly disagree $(-3)$ to strongly agree $(+3)($ alpha $=0.97)$.

(2) A multi-dimensional measure of PSM (Kim et al. 2013). This is a 16-item scale having four sub-dimensions, and it was validated based on a broad range of samples across the world. The four subdimensions are as follows: attraction to public service (APS; alpha $=0.90$ ), commitment to public values (CPV; alpha $=0.85)$, compassion $(\mathrm{COM}$; alpha $=0.93)$, and self-sacrifice $(\mathrm{SS} ;$ alpha $=$ 0.90). This construct has been included in this study to get an additional insight on how the PSM dimensions relate to the three attitude scales. Similar to the original scale, answers could be given on a 5-point Likert scale, ranging from strongly disagree $(-2)$ to strongly agree $(+2)$. A seventeenth item was included as an extra attention question for this data collection. Fit indices for the confirmatory factor analysis for the overall PSM scale are as follows: pvalue (Chi-square) $<0.001 ; \mathrm{CFI}=0.939$ ; $\mathrm{TLI}=0.925$; RMSEA $=0.078$; $\mathrm{p}$-value for the test that RMSEA is less than or equal to 0.05 is less than 0.001; SRMR $=0.051)$. Despite the fact that not all of them are within the strict cut-off boundaries as has been proposed by Marsh, Hau, and Wen (2004), they show a fairly good model fit and are close to the overall fit indices as reported by Kim et al. (2013).

(3) Citizens' trust in government (Grimmelikhuijsen and Knies 2017). This is a 9-item scale having the following three dimensions: competence $($ alpha $=0.93)$, benevolence $($ alpha $=$ 0.98), and integrity (alpha $=0.98$ ). Government as an abstract entity includes the entities of politicians, public services, and public servants. Hence, as a general measure, it can clarify how attitudes of these entities relate to this overreaching trust measurement. Grimmelikhuijsen and Knies (2017) proposes that the focal entity, such as a particular municipality, and the specific public task, such as airquality policy, can be varied and added to the list of items. Given the overall context of this study and the fact that data collection had happened in the U.S., items had been formulated to focus on the U.S. government. An example item is: 'The U.S. government carries out its duty very well'. Consistent with the original scale, a 5-point Likert scale was used, ranging from strongly disagree ($2)$ to strongly agree $(+2)$. The fit indices for the confirmatory factor analysis for the citizens' trust in government scale are as follows: p-value (Chi-square) = 0.23; $\mathrm{CFI}=0.998 ; \mathrm{TLI}=0.998 ;$ RMSEA $=0.024 ; \mathrm{p}$-value for test that RMSEA is less than or equal to 0.05 is 0.929 ; SRMR = 0.014). These fit indices are similar to, and to some extent even better than, the original study that has been conducted by Grimmelikhuijsen and Knies (2017). Despite the fact that it is not the purpose of this study, this analysis, thus, provides a replication in English, with a focus on the overall U.S. government, of their initial study from the Netherlands. In contrast to Grimmelikhuijsen and Knies (2017), the RMSEA value is within the expected 
boundaries as postulated by Marsh, Hau, and Wen (2004).

(4) Trust in government index. It is a 4-item index of the American National Election Studies

(http://www.electionstudies.org/nesguid e/gd-index.htm), in contrast to the original scale, in which 7 -answer points were used for all four questions and were numbered from 1 to 7 . The exact answeroption labels of the original 2, 3, or 4point scales in this index were presented on top of the scales and were outlined for the width of the scale. By asking all the four items as 7-point scales, this scale is more consistent with the other constructs in this study, and traditional multivariate analysis can be used (alpha $=$ 0.93). The inclusion of this scale provides an alternative measure of trust in the overreaching government category.

(5) Trust in sector organizations (Bader 2016; McDougle 2014). This is a construct that focuses on the trust that respondents have on the people working in different sectors. It is not a multi-item construct, but each of the items focus on a specific entity and are thus meant to explore different levels of trust for different sectors (government, nonprofits, and businesses). An example item is 'Most of the time, we can trust people in nonprofits to do what is right'. Consistent with the original formulation, a 5-point Likert scale was used.

(6) Public sector feeling (Weißmüller 2016). This is a 1-item scale in which respondents can express the negativity or positivity of their feelings towards the public sector. The item was measured with a semantic difference 7-point scale, with 'very negative' and 'very positive' as the end labels for the scale. For the context of this study, numeric labels were placed on top of each scale point, ranging from ' -3 ' to ' +3 '.

(7) Political party identification. This had been measured with two items, the extent to which the respondents considered themselves to be conservative or liberal, respectively. The two items were formulated as 'Do you consider yourself a conservative/ liberal?'. Five answer options were possible: 'definitely not' (-2), 'probably not' (-1), 'Might or might not' (0), 'probably yes' (1) 'definitely yes' (2). The liberal item was reversed, and both items were combined as a measure of conservative political identification. Similar measures have been used in other studies.

(8) Social desirability (Strahan and Gerbasi 1972). A 10-item construct, similar to the social desirability construct from the first data collection, but with 10 different items. Items were measured on a 7-point Likert scale with the values ranging from 'strongly disagree (-3)' to 'strongly agree (3)'.

Finally, the questionnaire contained demographic questions on gender, age, education, and employment.

\section{Results}

Table 2 reports the values for the measured constructs in this data collection.

From the correlational analysis (Figure 3), several insights about convergent and discriminant analysis can be developed. Relatedness of the three focal scales with each other is substantially high, especially the attitudes of the public sector and of the public servants $(r=0.72 ; p<0.05)$. Given this high relatedness, both scales will be referred to in the remainder of this text as the public service attitude scales. Moreover, attitudes of politicians correlate positively with attitudes 
Figure 3: Correlation plot (Wei and Simko 2017), with significant correlations $(p<.05)$ presented as numbers and pie-chars. Dark blue indicate strong positive correlations, dark red indicate strong negative correlations. The correlation plot shows the relatedness of the attitude scales with each other, and with other relevant concepts such as public service motivation, trust in government, and political orientation. < download here>

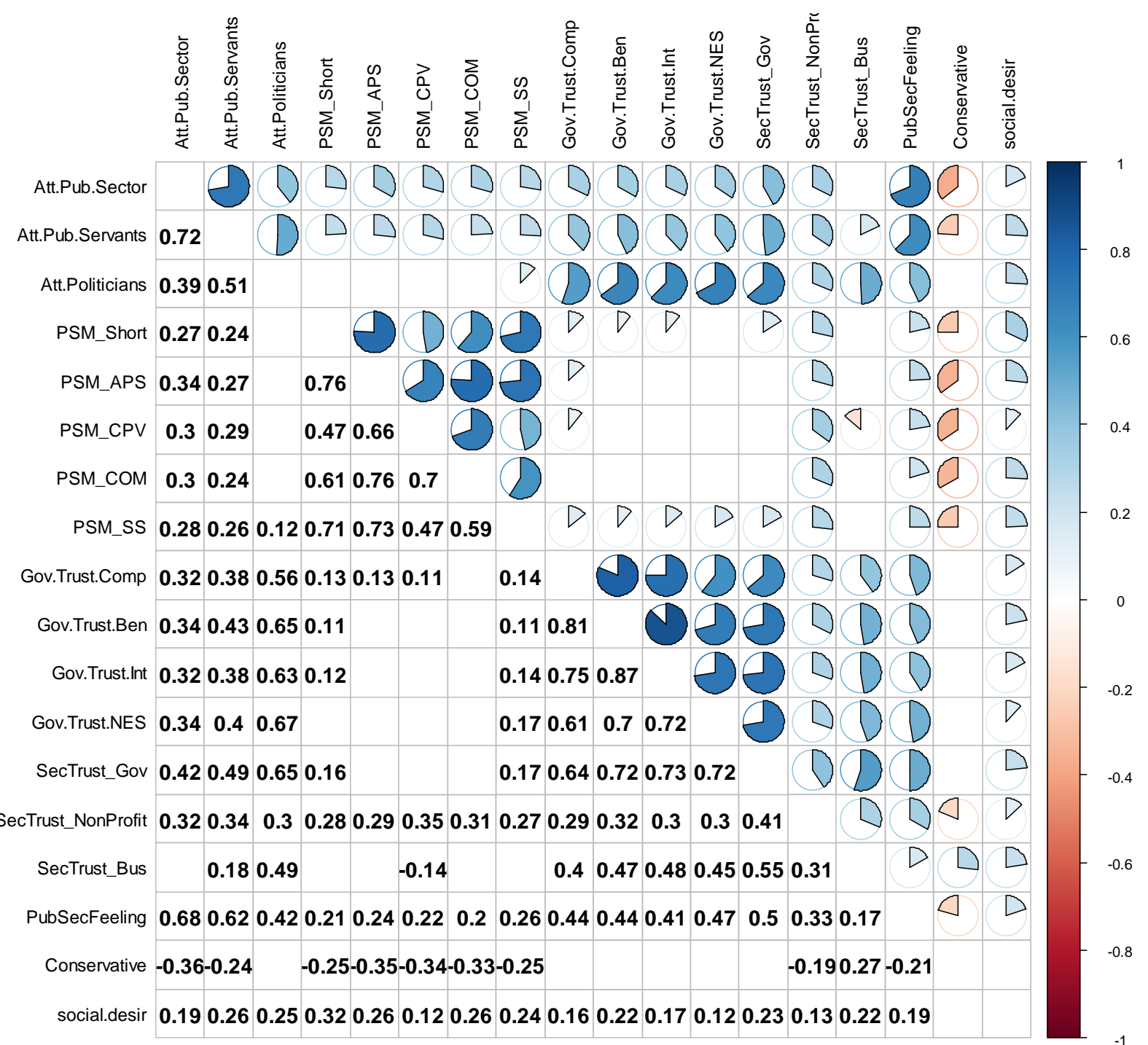

of the public sector $(0.39 ; \mathrm{p}<0.05)$ and of public servants $(0.51 ; \mathrm{p}<0.05)$.

The public service attitude scales both relate similarly to public service motivation and its four dimensions (values range between 0.25 and $0.34 ; \mathrm{p}<0.05)$, and it also relates to the different measures of government trust (correlation values range between 0.32 and $0.49 ; \mathrm{p}<0.05)$. As a consequence, public service attitude scales show consistent convergent validity with public service motivation and government trust.

In contrast, the attitudes of politicians only relate positively to the government trust measures (even stronger than public service attitudes scales do; correlation values range from 0.56 to 0.67 ; $<<0.05$ ), and not with public service motivation (no significant correlations). This distinct relatedness supports the discriminant validity of the scale 
on the attitudes to politicians and suggests that the government has indeed a stronger political connotation than the public sector and public servants entities.

Moreover, when looking at trust in the different sectors (Bader 2016), all the three attitude scales correlate positively with trust in government, with the highest correlation for the attitudes to the politicians $(\mathrm{r}=0.65 ; \mathrm{p}$ $<0.05)$. This supports convergent validity. Correlations are also positive, but they are less strong for trust in the non-profit sector (values are around 0.30). However, the public service attitude scales do not correlate or correlate only to a limited extent to the trust in the businesses $(r=0.18 ; \mathrm{p}<0.05)$, supporting discriminant validity of these public service attitude scales. Interestingly, for attitudes towards politicians, a (stronger) significant correlation, as compared to the public service attitudes has been observed for trust in businesses $(r=0.49 ; \mathrm{p}<0.05)$.

The attitude towards the public sector and the public servants relate negatively to political conservatism, which is also consistent with the conservative political program in the U.S. to reduce public services and limit the number of public servants. No correlation exists between the attitudes towards politicians and conservatism.

Despite the fact that correlating items with the social desirability construct in the first data collection were removed, the overall attitude scales still correlated to a limited extent, but they significantly correlated with the social desirability construct (values range between 0.19 and $0.26 ; \mathrm{p}<0.05$ ). These are relatively small effect sizes, but further critical reflection is needed.

\section{Step 4: Assessment of distinctiveness of the three focal scales.}

Despite the fact that all the three scales focused on distinct entities in the government and public service field, it is valuable to explore the extent to which all three scales are distinct from each other from a measurement perspective. Therefore, scale validation tests that are commonly used to get an insight into the discriminant validity of construct dimensions can inform us about the distinctiveness in measurement of the three scales. Therefore, exploratory factor analysis had been done on Samples 1 and 2, and confirmatory factor analysis had been done on Sample 3. However, it has to be noted that the scales in this study are not seen as dimensions of an overall multi-dimensional construct. Therefore, these tests rather explore theoretical and/or mentally associated relatedness of these entities, and the interchangeability of these scales.

From the correlational analysis above, distinctiveness of the attitudes towards politicians from the attitudes towards public services can preliminarily be confirmed due to different relatedness with the citizen's trust in the government and the motivation to engage in public service. However, attitudes towards the public sector and towards the public servants seem substantially less distinct (at least from the perspective of the measurement scale). This is also supported by the outputs of both the exploratory (Samples 1 and 2) and the confirmatory factor analyses (Sample 3) based on the remaining items. For example, when conducting an exploratory factor analysis (Maximum Likelihood, 3 factors extracted, promax rotation, loading cut-off $=0.3$ ) for the stream of completely randomized item order (Sample 1), one factor clearly groups a set of politician attitude items, while the other two factors group combinations of the attitude towards the public sector and towards public servants (one factor with positively formulated items, and one with negatively formulated items). Hence, when asked in a combined manner, measures of attitudes towards the public sector and towards public servants are not very distinct. The exploratory factor analysis in the second sample, i.e. when items are 
Table 3: Item loadings for the three 4-item shortened scales, with Cronbach's alpha values for Sample (3).

\begin{tabular}{|c|c|c|}
\hline Code & Item & $\begin{array}{c}\text { Item } \\
\text { loading }\end{array}$ \\
\hline \multicolumn{3}{|c|}{ Public sector attitudes $(\alpha=.84)$} \\
\hline PubSec03 & The public sector is disconnected from the people it serves. & .695 \\
\hline PubSec05 & The public sector should be reduced. & .795 \\
\hline PubSec08 & The public sector is a waste of money. & .833 \\
\hline PubSec12 & The public sector is effective. & -.688 \\
\hline \multicolumn{3}{|c|}{ Public servants attitudes $(\alpha=.90)$} \\
\hline PubServ01 & Public servants are corrupt. & .878 \\
\hline PubServ07 & Too many public servants are selfish. & .871 \\
\hline PubServ11 & Public servants are overpaid. & .743 \\
\hline PubServ12 & Public servants are power-hungry. & .859 \\
\hline \multicolumn{3}{|c|}{ Politician attitudes $(\alpha=.92)$} \\
\hline Pol01 & Politicians are selfish. & .873 \\
\hline Pol03 & Politicians are greedy. & .910 \\
\hline Pol11 & Politicians are liars. & .851 \\
\hline Pol13 & Politicians are power-hungry. & .813 \\
\hline
\end{tabular}

grouped as per entity, shows more clearly the factor loading that is consistent with the entities.

When performing confirmatory factor analysis for the third sample, with three factors (one per entity) and no cross-loading items specified, model fit is not sufficient to conclude clear discriminant validity $(\mathrm{CFI}=$ $0.811 ; \mathrm{TLI}=0.795 ; \mathrm{RMSEA}=0.102 ; \mathrm{BIC}=$ 30593.083). However, model fit is still better as compared to the two-factor model with the items of attitudes towards public sector and public servants in one factor (Chi-Square difference $=538.36 ; \mathrm{df}=2 ; \mathrm{p}<0.001 ; \mathrm{BIC}=$ 31119.799), and compared to a single-factor model (Chi-Square difference $=1439.9$; $\mathrm{df}=$ $3 ; \mathrm{p}<0.001 ; \mathrm{BIC}=32015.511)$. The modification indices in the three-dimensional models indeed suggest allowing crossloadings, mainly between the scales of the attitudes towards public sector and towards public servants. Hence, these factor analyses show that scale distinctiveness is low, or nonexistent for the attitudes towards public sector and towards public servants. This has likely to do with the fact that servants are a major part of the sector, and scale items are, therefore, driven by the same mental framework, or latent cognition of public services as a whole. However, from a practical point, this means that both scales are to a large extent interchangeable (e.g. when the research question does not particularly focus on one of the specific entities, they might be combined as a single scale, or used interchangeably). Table 1 reports the factor loadings of the confirmatory factor analysis of Sample 3.

\section{Step 5: Shortened scales for practical use}

As the aim of this study is to develop three scales that can easily be integrated in other studies, this step focuses on selecting items 
for more concise scales that have enough internal consistency. Based on Sample 2, four items per scale were selected based on a generalized least squares factor analysis with items regressed on a single factor (Giallousis 2015). The four best loading items per scale were selected. In addition, Cronbach's alpha for these items based on sample 3 are reported as a cross-sample validation check. The selected items, loading and Cronbach's alpha values are reported in Table 3 . These reduced scales can thus be used as an overall measures of attitude towards the three focal entities. Moreover, a correlational analysis, similar to Step 3, but with shortened scales results in a very similar finding, which can be consulted in the online appendix. Moreover, it has to be noted that most of the remaining items were formulated in a negative manner. It is thus recommended to reverse the loadings or the item scores when using the scale in other research designs, as positive scores are then expressing positive attitudes.

\section{Discussion and further research}

The aim of this study was to develop three related attitude scales and test their relatedness with a set of core constructs from the literature regarding public management. These scales can, in turn, be used in the growing body of literature that deals with how the attitudes of citizens towards the public field explain their behavior. Despite the fact that a clear conceptual distinction is possible to be made between the focal entities that are researched, attitudes and measures of the attitudes can be overlapping and mutually influencing (Van de Walle 2008). Consequently, the attitudes towards the public sector in general and public servants as a part of this sector are highly related, and the scales are not clearly distinct. Potentially, social processes of self-selection and socialization of public servants within the sector result in related perceptions among citizens, which, in turn, explains the related attitudes towards these two entities (Becker and Connor 2005; De Cooman et al. 2011).

Convergent validity could be derived from a relatedness analysis with other public management constructs. The relatedness of trust in government with all the three attitude scales, but especially with the attitudes towards politicians, suggest that the term "government" is broader, and it groups both the political aspect as well as the public service aspect. In contrast, the distinct relatedness with public service motivation, which is more focused on the managerial and operational public service aspect (Perry and Wise 1990) shows that attitudes towards politician are unrelated to concrete motivations.

Moreover, motivation towards public service is not only related or restricted to the public service or the field of government. For example, public service motivation is positively correlated with trust in non-profit organizations (correlations range between 0.28 and 0.35), and less with trust in businesses and government (most correlations are not significant). High public service motivation can thus be fulfilled through participation and involvement in various types of socially oriented organizations, from which some public-sector organizations are an option (Vandenabeele 2007; Vogel and Willems, 2020).

Political orientation, i.e. being rather conservative versus being liberal, also relates differently to the attitudes towards the public sector and the attitudes towards public servants on the one hand, and to the attitudes towards politician on the other hand. Inherent to the conservative political ideology in the U.S., a rather negative attitude exists towards the public sector and its employees (Bean and Papadakis 1998).

A critical note has to be made about the observation that (almost) all constructs in the second wave of the data collection still 
correlate to some extent with a measure of social desirability. Potentially, the common question type of the Likert scale items might be at the origin of this level of relatedness. Therefore, further exploration and validations in the field of public management scales could not only consider the item content, but also alternative scale formats, such as the Guttman scale and the semantic differential scale. Such elaboration can continue the clarification of whether the measured relatedness of constructs is the result of substantial relationships or of the tools that we use (George and Pandey 2017).

From a theoretical perspective, the newly developed scales can assist in the advancement of a broader research agenda on the behavior of citizens in relation to public services and the government in general. The attitudes of citizens are the result of culture, wide-spread beliefs, and accumulated personal experiences (James 2011). Attitudes can, thus, be included in further studies to explain the additional variance in individual differences for citizen-bureaucracy interactions, in particular, in the choice pertaining to engaging in citizen participation initiatives and/or public service coproduction (Clark and Jang 2013; Yang and Callahan 2007).

Attitudes can also change due to new experiences and information (Eagly and Chaiken 1993). Hence, attitudes are also an important focal concept which can be explained as a dependent variable, for example in the context of public-sector performance evaluations. Initial attitudes can potentially be an important explaining factor, especially in the field of public-performance assessments and citizen-satisfaction evaluations (Van Ryzin et al. 2004; Morgeson 2013). In turn, the impact on attitudes of recurrent changes in satisfaction as a result of experienced performance which deviates from initial expectation could also be tested. Similarly, in the context of citizen participation and co-production, the experience and the obtained information through this participation might eventually influence the attitudes of citizens (Halachmi and Holzer 2010).

\section{Limitations}

In addition to the validation tests in this study, such as item quality, scale reliability, and construct validity (convergent and discriminant validity), several further validation steps could be performed. Despite the fact that citizen attitudes can change over time, further steps could focus on test-retest validity. In addition, further steps are also needed to test the predictive validity, for example, based on the hypothesized effects in the previous section that attitudes might explain the decision to engage in the participation of citizens and co-production initiatives; or attitudes might affect how citizens form an opinion on particular publicservice experiences, and with that their satisfaction evaluations.

The open-source nature of this project, with the data being fully available, contributes to this philosophy of further testing and scrutinizing these attitude scales in public management research.

\section{Conclusion}

Three related scales on public sector, public servants, and politician attitudes were developed and validated. Attitude scales for the public sector and public servant respectively show low measurement distinctiveness. In contrast, attitudes towards politicians are more distinct also with respect to relatedness with other government-focused constructs. 


\section{References}

Albrecht, Simon, and Anthony Travaglione. 2003. "Trust in Public-Sector Senior Management." The International Journal of Human Resource Management 14 (1). Routledge: 76-92. doi:10.1080/09585190210158529.

Alwin, Duane F. 1997. "Feeling Thermometers Versus 7-Point Scales: Which Are Better?" Sociological Methods \& Research 25 (3): 318-40.

Bader, Michael D. M. 2016. Diversity in the d.C. Area: Findings from the 2016 d.C. Area Survey. 14th ed. Vol. 14. 14th Ser. CLALS working paper series. http://www.american.edu/spa/metro-policy/upload/DC-AreaStudy_Bader.pdf.

Bean, Clive, and Elim Papadakis. 1998. "A Comparison of Mass Attitudes Towards the Welfare State in Different Institutional Regimes, 1985-1990.” International Journal of Public Opinion Research 10 (3): 211-36. doi:10.1093/ijpor/10.3.211.

Becker, Boris W., and Patrick E. Connor. 2005. "Self-Selection or Socialization of Public- and Private-Sector Managers? A Cross-Cultural Values Analysis." Journal of Business Research 58 (1): 111-13.

Beirão, Gabriela, and J.A. Sarsfield Cabral. 2007. "Understanding Attitudes Towards Public Transport and Private Car: A Qualitative Study.” Transport Policy 14 (6): 478-89. doi:10.1016/j.tranpol.2007.04.009.

Billiet, Jaak B., and Eldad Davidov. 2008. "Testing the Stability of an Acquiescence Style Factor Behind Two Interrelated Substantive Variables in a Panel Design.” Sociological Methods \& Research 36 (4): 542-62.

Bollen, Kenneth, and Lennox Richard. 1991. "Conventional Wisdom on Measurement: A Structural Equation Perspective.” Psychological Bulletin 110 (2): 305-14.

Borsboom, Denny, Gideon J. Mellenbergh, and Jaap van Heerden. 2003. "Theoretical Status of Latent Variables." Psychological Review 110 (2): 203-19.

Choi, Yujin. 2017. "Work Values, Job Characteristics, and Career Choice Decisions: Evidence from Longitudinal Data." The American Review of Public Administration 47 (7): 779-96. doi:10.1177/0275074016653469.

Christensen, Tom, and Per Lægreid. 2003. Trust in Government - the Significance of Attitudes Towards Democracy, the Public Sector and Public Sector Reforms. 43284th Ser. Stein Rokkan Centre for Social Studies. http://hdl.handle.net/1956/1400.

Clark, Jeffrey L., Benjamin Y. AND Brudney, and Sung-Gheel Jang. 2013. "Coproduction of Government Services and the New Information Technology: Investigating the Distributional Biases." Public Administration Review 73 (5): $687-701$.

De Cooman, Rein, Sara De Gieter, Roland Pepermans, and Marc Jegers. 2011. "A Cross-Sector Comparison of Motivation-Related Concepts in for-Profit and Not-for-Profit Service Organizations." Nonprofit and Voluntary Sector Quarterly 40 (2): 296-317.

DeVellis, Robert F. 2003. Scale Development: Theory and Applications. 2nd ed. London: Sage Publications.

Eagly, Alice. H., and Shelly Chaiken. 1993. The Psychology of Attitudes. Orlando, FL: Harcourt Brace Jovanovich College Publishers.

—. 2007. "The Advantages of an Inclusive Definition of Attitude." Social Cognition 25 (5): 582-602.

Ek, Kristina. 2005. "Public and Private Attitudes Towards 'Green' Electricity: The Case of Swedish Wind Power." Energy Policy 33 (13): 1677-89. doi:10.1016/j.enpol.2004.02.005.

Fischer, Donald G., and Carol Fick. 1993. "Measuring Social Desirability: Short Forms of the Marlowe-Crowne Social Desirability Scale." Educational and Psychological Measurement 53 (2): 417-24. doi:10.1177/0013164493053002011.

Foddy, William. 1993. Constructing Questions for Interviews and Questionnaires: Theory and Practice in Social Research. Cambridge: Cambridge University Press; Cambridge University Press.

Gawronski, Bertram. 2007. “Attitudes Can Be Measured! But What Is an Attitude?” Social Cognition 25 (5): 573-81. 
George, Bert, and Sanjay K. Pandey. 2017. "We Know the Yin—But Where Is the Yang? Toward a Balanced Approach on Common Source Bias in Public Administration Scholarship." Review of Public Personnel Administration 37 (2): 245-70. doi:10.1177/0734371X17698189.

Giallousis, Nikolaos. 2015. Scale: Likert Type Questionnaire Item Analysis. https://CRAN.Rproject.org/package $=$ Scale.

Gould-Williams, Julian. 2004. "The Effects of 'High Commitment' Hrm Practices on Employee Attitude: The Views of Public Sector Workers.” Public Administration 82 (1): 63-81. doi:10.1111/j.0033-3298.2004.00383.x.

Goulet, Laurel R., and Margaret L Frank. 2002. "Organizational Commitment Across Three Sectors: Public, NonProfit, and for-Profit.” Public Personnel Management 31 (2): 201-11.

Grimmelikhuijsen, Stephan, and Eva Knies. 2017. "Validating a Scale for Citizen Trust in Government Organizations." International Review of Administrative Sciences 83 (3): 583-601. doi:10.1177/0020852315585950.

Grimmelikhuijsen, Stephan, Sebastian Jilke, Asmus Leth Olsen, and Lars Tummers. 2017. "Behavioral Public Administration: Combining Insights from Public Administration and Psychology." Public Administration Review 77 (1): 45-56.

Halachmi, Arie, and Marc Holzer. 2010. "Citizen Participation and Performance Measurement: Operationalizing Democracy Through Better Accountability.” Public Administration Quarterly 34 (3): 378-99.

Henn, Matt, Mark Weinstein, and Sarah Forrest. 2005. "Uninterested Youth? Young People's Attitudes Towards Party Politics in Britain.” Political Studies 53 (3): 1467-9248. doi:10.1111/j.1467-9248.2005.00544.x.

Inthorn, Sanna, and John Street. 2011. "Simon Cowell for Prime Minister'? Young Citizens' Attitudes Towards Celebrity Politics." Media, Culture \& Society 33 (3): 479-89. doi:10.1177/0163443711398765.

Irvin, Renée A., and John Stansbury. 2004. "Citizen Participation in Decision Making: Is It Worth the Effort?" Public Administration Review 64 (1): 55-65.

James, Oliver. 2011. "Managing Citizens' Expectations of Public Service Performance: Evidence from Observation and Experimentation in Local Government.” Public Administration 89 (4): 1419-35.

James, Oliver, Sebastian R. Jilke, and Gregg G. Van Ryzin. 2017. "Behavioural and Experimental Public Administration: Emerging Contributions and New Directions." Public Administration 95 (4): 865-73. doi:10.1111/padm.12363.

Jilke, Sebastian. 2017. "Citizen Satisfaction Under Changing Political Leadership: The Role of Partisan Motivated Reasoning." Governance,--. doi:10.1111/gove.12317.

Kim, Sangmook, Wouter Vandenabeele, Bradley E. Wright, Lotte Bøgh Andersen, Francesco Paolo Cerase, Robert K. Christensen, Céline Desmarais, et al. 2013. "Investigating the Structure and Meaning of Public Service Motivation Across Populations: Developing an International Instrument and Addressing Issues of Measurement Invariance." Journal of Public Administration Research and Theory 23 (1): 79-102. doi:10.1093/jopart/mus027.

Kolsaker, Ailsa, and Liz Lee-Kelley. 2008. "Citizens' Attitudes Towards E-government and E-governance: A Uk Study.” International Journal of Public Sector Management 21 (7): 723-38. doi:10.1108/09513550810904532.

Lee, Geon, and Do Lim Choi. 2016. "Does Public Service Motivation Influence the College Students' Intention to Work in the Public Sector? Evidence from Korea." Review of Public Personnel Administration 36 (2): 145-63. doi:10.1177/0734371X13511974.

Marsh, Herbert W., Kit-Tai Hau, and Zhonghlin Wen. 2004. "In Search of Golden Rules: Comment on HypothesisTesting Approaches to Setting Cutoff Values for Fit Indexes and Dangers in Overgeneralizing Hu and Bentler's (1999) Findings." Structural Equation Modeling 11 (2): 320-41.

Marvel, John D. 2016. “Unconscious Bias in Citizens' Evaluations of Public Sector Performance.” Journal of Public Administration Research and Theory 26 (1): 143-58.

McDougle, Lindsey. 2014. "Understanding Public Awareness of Nonprofit Organizations: Exploring the Awarenessconfidence Relationship.” International Journal of Nonprofit and Voluntary Sector Marketing 19 (3): 187-99. 
Morgeson, Forrest V. III. 2013. "Expectations, Disconfirmation, and Citizen Satisfaction with the Us Federal Government: Testing and Expanding the Model." Journal of Public Administration Research and Theory 23 (2): 289-305.

Nielsen, Hans Jorgen. 1981. "Size and Evaluation of Government: Danish Attitudes Towards Politics at Multiple Levels of Government." European Journal of Political Research 9 (1): 47-60. doi:10.1111/j.14756765.1981.tb00588.x.

Norman, Geoff. 2010. "Likert Scales, Levels of Measurement and the 'Laws' of Statistics." Advances in Health Sciences Education 15 (5): 625-32.

Olsen, Asmus Leth. 2015. "Citizen (Dis) Satisfaction: An Experimental Equivalence Framing Study." Public Administration Review 75 (3): 469-78.

Pandey, Sanjay K., David H. Coursey, and Donald P. Moynihan. 2007. "Organizational Effectiveness and Bureaucratic Red Tape: A Multimethod Study." Public Performance \& Management Review 30 (3): 398-425. doi:10.2753/PMR1530-9576300305.

Perry, James L., and Lois Recascino Wise. 1990. "The Motivational Bases of Public Service.” Public Administration Review 50 (3): 367-73.

R Core Team. 2017. R: A Language and Environment for Statistical Computing. Vienna, Austria: R Foundation for Statistical Computing. https://www.R-project.org/.

Revelle, William. 2017. Psych: Procedures for Psychological, Psychometric, and Personality Research. Evanston, Illinois: Northwestern University. https://CRAN.R-project.org/package=psych.

Roberts, Nancy. 2004. "Public Deliberation in an Age of Direct Citizen Participation." American Review of Public Administration 34: 315-52.

Rosseel, Yves. 2012. "lavaan: An R Package for Structural Equation Modeling." Journal of Statistical Software 48 (2): 1-36. http://www.jstatsoft.org/v48/i02/.

Ryzin, Gregg G. Van. 2004. "The Measurement of Overall Citizen Satisfaction.” Public Performance \& Management Review 27 (3): 9-28. doi:10.2307/3381143.

Scherpenzeel, Annett C., and Willem E. Saris. 1997. "The Validity and Reliability of Survey Questions: A MetaAnalysis of Mtmm Studies." Sociological Methods \& Research 25 (3): 341-83.

Strahan, Robert, and Kathleen Carrese Gerbasi. 1972. "Short, Homogeneous Versions of the Marlow-Crowne Social Desirability Scale.” Journal of Clinical Psychology 28 (2): 191-93. doi:10.1002/1097-4679(197204)28:2<191::AIDJCLP2270280220>3.0.CO;2-G.

Thurstone, Louis Leon. 1928. “Attitudes Can Be Measured.” American Journal of Sociology 33 (4): 529-54.

Van de Walle, Steven. 2004. "Context-Specific Images of the Archetypical Bureaucrat: Persistence and Diffusion of the Bureaucracy Stereotype." Public Voices 7 (1): 3-12.

Van de Walle, Steven. 2008. "Perceptions of Corruption as Distrust? Cause and Effect in Attitudes Towards Government." In Ethics and Integrity and the Politics of Governance, edited by L. Huberts, C. Jurkiewicz, and J. Maesschalck, 215-36. Cheltenham: Edward Elgar. https://ssrn.com/abstract=1307673.

Van de Walle, Steven, and Gregg G. Van Ryzin. 2011. "The Order of Questions in a Survey on Citizen Satisfaction with Public Services: Lessons from a Split-ballot Experiment.” Public Administration 89 (4): 1436-50.

Van Ryzin, Gregg G., Douglas Muzzio, Stephen Immerwahr, Lisa Gulick, and Eve Martinez. 2004. "Drivers and Consequences of Citizen Satisfaction: An Application of the American Customer Satisfaction Index Model to New York City." Public Administration Review 64 (3): 331-41.

Vandenabeele, Wouter. 2007. "Toward a Public Administration Theory of Public Service Motivation: An Institutional Approach.” Public Management Review 9 (4): 545-56.

Vandenabeele, Wouter, and Julia Penning de Vries. 2013. "Validating a Global Measure of Public Service Motivation: Assessing Measurement Invariance.” Aarhus, Demark: Public Management Research Conference; Public Management Research Conference. 
Vigoda, Eran. 2000. "Organizational Politics, Job Attitudes, and Work Outcomes: Exploration and Implications for the Public Sector.” Journal of Vocational Behavior 57 (3): 326-47. doi:10.1006/jvbe.1999.1742.

Vogel, D., \& Willems, J. 2020. The Effects of Making Public Service Employees Aware of Their Prosocial and Societal Impact: A Microintervention. Journal of Public Administration Research and Theory. Accepted (2 Dec. 2019) Open data / Open code: https://osf.io/w97h4/ DOI: https://doi.org/10.1093/jopart/muz044

Wei, Taiyun, and Viliam Simko. 2017. $R$ Package "Corrplot": Visualization of a Correlation Matrix. https://github.com/taiyun/corrplot.

Weißmüller, Kristina. 2016. "The Grass Is Greener on the Other Side: Experimental Evidence on the Asymmetric Nature of the Anti-Public Sector Bias and the Heuristic Formation of Public Opinion.” Poznan, Poland: IPSA 24th World Congress of Political Sciences; IPSA 24th World Congress of Political Sciences.

Whitaker, Gordon P. 1980. "Coproduction: Citizen Participation in Service Delivery." Public Administration Review 40 (3): $240-46$.

Willems, Jurgen. 2014. "Antecedents or Effects of Being a Manager in the Nonprofit, Public or Private Sector." Nonprofit Management \& Leadership 25 (2): 183-89.

Willems, Jurgen. 2017. Citizen Participation and Coproduction Across Countries: The Case of Parent Participation in Education (July 18, 2017). Available at SSRN: https://ssrn.com/abstract $=3004671$ or http://dx.doi.org/10.2139/ssrn.3004671

Willems, Jurgen. 2018. What we think about public servants: Stereotypical associations about public service professions. Academy of Management Proceedings. 2018 (1): 10462

Willems, Jurgen. (2020), Public servant stereotypes: It is not (at) all about being lazy, greedy, and corrupt. Public Administration. https://doi.org/10.1111/padm.12686

Willems, Jurgen. 2020. "Public Servants: Stereotypes, attitudes, reputation, and stigmata." Open Science Framework, Retrieved from https://osf.io/xky93/ (Open Data)

Willems, Jurgen. 2020. Cognitive word associations for "public servant" in US. figshare. Figure. https://doi.org/10.6084/m9.figshare.12505415 (Open Figure - Figure 1).

Willems, Jurgen. 2020. Cognitive word associations for "politician" in US. figshare. Figure. https://doi.org/10.6084/m9.figshare.12505430 (Open Figure - Figure 2).

Willems, Jurgen (2020): Correlation plot - for attitudes towards the public sector, public servants, and politicians; and Public service motivation, Trust in government, Political orientation, Social desirability, etc. figshare. Figure. https://doi.org/10.6084/m9.figshare.12571232

Wright, Bradley E., Shahidul Hassan, and Robert K. Christensen. 2017. "Job Choice and Performance: Revisiting Core Assumptions About Public Service Motivation." International Public Management Journal 20 (1): 108-31. doi:10.1080/10967494.2015.1088493.

Yang, Kaifeng, and Kathe Callahan. 2007. "Citizen Involvement Efforts and Bureaucratic Responsiveness." Public Administration Review 67 (2): 249-64. 
Table 1 - Complete: Full list of items, with factor loadings of CFA for Sample 3

\begin{tabular}{|c|c|c|c|c|c|c|c|}
\hline Code & Item & $\begin{array}{c}\text { Item } \\
\text { Loading }^{\mathrm{a}}\end{array}$ & s.e. & $\begin{array}{c}\text { CI } \\
\text { lower }\end{array}$ & $\begin{array}{c}\text { CI } \\
\text { upper }\end{array}$ & $\begin{array}{c}\text { Variance } \\
\text { Extracted } \\
\left(\mathrm{R}^{2}\right)\end{array}$ & Comment \\
\hline \multicolumn{8}{|c|}{ Public sector attitudes } \\
\hline PubSec01 & The public sector is less efficient than the private sector. & $1.000^{\mathrm{b}}$ & & 1.000 & 1.000 & .415 & \\
\hline PubSec02 & The public sector is not customer oriented. & .909 & .089 & .734 & 1.083 & .389 & \\
\hline PubSec03 & The public sector is disconnected from the people it serves. & 1.047 & .091 & .869 & 1.226 & .515 & \\
\hline PubSec04 & The public sector is accessible to all citizens & -.886 & .084 & -1.05 & -.722 & .423 & \\
\hline PubSec05 & The public sector should be reduced. & 1.147 & .096 & .958 & 1.336 & .560 & \\
\hline PubSec06 & The public sector is trustworthy. & -.956 & .079 & -1.111 & -.8 & .576 & \\
\hline PubSec07 & The public sector is necessary to maintain quality of life in our country. & -.816 & .075 & -.964 & -.669 & .447 & \\
\hline PubSec08 & The public sector is a waste of money. & 1.214 & .098 & 1.022 & 1.406 & .619 & \\
\hline PubSec09 & The public sector provides crucial services in our society. & -.777 & .07 & -.914 & -.64 & .472 & \\
\hline PubSec10 & (The public sector is at least as professional as the private sector.) & & & & \multicolumn{3}{|c|}{ Deleted in Step 2 (high social desirability) } \\
\hline PubSec11 & The public sector is innovative. & -.905 & .085 & -1.072 & -.738 & .428 & \\
\hline PubSec12 & The public sector is effective. & -1.037 & .084 & -1.202 & -.871 & .609 & \\
\hline PubSec13 & (The public sector is too bureaucratic.) & & & & \multicolumn{3}{|c|}{ Deleted in Step 2 (high social desirability) } \\
\hline PubSec14 & The public sector employs more people than necessary. & 1.127 & .100 & .930 & 1.323 & .485 & \\
\hline PubSec15 & (The public sector has too many rules and red tape.) & & & & \multicolumn{3}{|c|}{ Deleted in Step 2 (low consistency) } \\
\hline \multicolumn{8}{|c|}{ Public servants attitudes } \\
\hline PubServ01 & Public servants are corrupt. & $1.000^{\mathrm{b}}$ & & 1.000 & 1.000 & .736 & \\
\hline PubServ02 & (Public servants are less competent than employees in the for-profit sector.) & & & & \multicolumn{3}{|c|}{ Deleted in Step 2 (high social desirability) } \\
\hline PubServ03 & (Public servants are naïve.) & & \multicolumn{5}{|c|}{ Deleted in Step 2 (low consistency and high social desirability) } \\
\hline PubServ04 & Public servants have easy jobs. & .561 & .061 & .44 & .681 & .225 & \\
\hline PubServ05 & (I think of public servants as very motivated people.) & & & & \multicolumn{3}{|c|}{ Deleted in Step 2 (low consistency) } \\
\hline PubServ06 & Most public servants can be typified as dedicated. & -.736 & .047 & -.827 & -.644 & .527 & \\
\hline PubServ07 & Too many public servants are selfish. & 1.033 & .051 & .934 & 1.133 & .719 & \\
\hline PubServ08 & Public servants are political puppets. & .965 & .053 & .861 & 1.069 & .629 & \\
\hline PubServ09 & Public servants are lazy. & .897 & .054 & .79 & 1.003 & .560 & \\
\hline PubServ10 & Most public servants are helpful. & -.811 & .048 & -.904 & -.718 & .581 & \\
\hline PubServ11 & Public servants are overpaid. & 1.043 & .059 & .927 & 1.16 & .603 & \\
\hline PubServ12 & Public servants are power-hungry. & 1.02 & .054 & .914 & 1.127 & .657 & \\
\hline PubServ13 & (Public servants are altruistic.) & & & & \multicolumn{3}{|c|}{ Deleted in Step 2 (low consistency) } \\
\hline PubServ14 & Public servants are accessible. & -.664 & .051 & -.764 & -.564 & .400 & \\
\hline
\end{tabular}


PubServ15 Public servants are role models.

\section{Politician}

Pol01

Pol02

Pol03

Pol04

Pol05

Pol06

Pol07

Pol08

Pol09

Pol10

Pol11

Pol12

Pol13

Poll4

Pol15

\section{Politicians are selfish.}

(Politicians are overpaid.)

Politicians are greedy.

(Politicians are naïve.)

Politicians are altruistic.

(Politicians are manipulative.)

Politicians are liars.

(Politicians have easy jobs.)

Politicians are power-hungry.
(I think of politicians as very motivated people.)

(Politicians talk too much and do too little.)

(Politicians are disconnected from the people they serve.)

Politicians want to improve the world.

(Politicians are very motivated people.)

(Politicians only focus on the well-being of a small group of citizens.)

\begin{tabular}{|c|c|c|c|c|}
\hline-.616 & .054 & -.722 & -.51 & .325 \\
\hline \multirow[t]{2}{*}{$1.000^{\mathrm{b}}$} & & 1.000 & 1.000 & .784 \\
\hline & & & \multicolumn{2}{|c|}{ Deleted in Step 2 (high social desirability) } \\
\hline \multirow[t]{3}{*}{1.011} & .042 & .930 & 1.093 & .822 \\
\hline & \multicolumn{4}{|c|}{ Deleted in Step 2 (low consistency) } \\
\hline & \multicolumn{4}{|c|}{ Deleted in Step 2 (low consistency and high social desirability) } \\
\hline \multirow[t]{4}{*}{-.412} & .071 & -.55 & -.273 & .100 \\
\hline & & & \multicolumn{2}{|c|}{ Deleted in Step 2 (high social desirability) } \\
\hline & & & \multicolumn{2}{|c|}{ Deleted in Step 2 (high social desirability) } \\
\hline & & & \multicolumn{2}{|c|}{ Deleted in Step 2 (high social desirability) } \\
\hline-.795 & .06 & -.912 & -.678 & .402 \\
\hline \multirow[t]{2}{*}{.948} & .041 & .867 & 1.029 & .774 \\
\hline & & & \multicolumn{2}{|c|}{ Deleted in step 2 (low consistency) } \\
\hline \multirow[t]{2}{*}{.862} & .046 & .772 & .953 & .625 \\
\hline & & & $\begin{array}{r}L \\
\text { leted }\end{array}$ & $\begin{array}{l}d \text { in Step } 2 \text { (low consistency) } \\
2 \text { (high social desirability) }\end{array}$ \\
\hline
\end{tabular}

CI: confidence interval

s.e.: Standard error

${ }^{a}$ Factor loadings of the confirmatory factor analysis are reported, based on Sample 3; i.e. without the items that were deleted in Step 2 (see comments column).

${ }^{\mathrm{b}}$ Reference loadings (specified to be ' 1 ') 